\title{
Measurement of peripapillary retinal nerve fiber layer thickness and macular thickness in anisometropia using spectral domain optical coherence tomography: a prospective study
}

\author{
This article was published in the following Dove Press journal: \\ Clinical Ophthalmology \\ 23 February 2017 \\ Number of times this article has been viewed
}

\author{
Neha Singh \\ Jolly Rohatgi \\ Ved Prakash Gupta \\ Vinod Kumar
}

Department of Ophthalmology, University College of Medical

Sciences, Delhi, India
Correspondence: Neha Singh I/252, Rasmi Khand, Sharda Nagar

Yojana, Lucknow, Uttar Pradesh, India

Tel +9| 9958552139

Email nhsngh.89@gmail.com
Purpose: To study whether there is a difference in central macular thickness (CMT) and peripapillary retinal nerve fiber layer (RNFL) thickness between the two eyes of individuals having anisometropia $>1$ diopter (D) using spectral domain optical coherence tomography (OCT).

Material and methods: One hundred and one subjects, 31 with myopic anisometropia, 28 with astigmatic anisometropia, and 42 with hypermetropic anisometropia, were enrolled in the study. After informed consent, detailed ophthalmological examination was performed for every patient including cycloplegic refraction, best corrected visual acuity, slit lamp, and fundus examination. After routine ophthalmic examination peripapillary RNFL and CMT were measured using spectral domain OCT and the values of the two eyes were compared in the three types of anisometropia. Axial length was measured using an A Scan ultrasound biometer (Appa Scan-2000).

Results: The average age of subjects was $21.7 \pm 9.3$ years. The mean anisometropia was $3.11 \pm 1.7 \mathrm{D}$ in myopia; $2 \pm 0.99 \mathrm{D}$ in astigmatism; and $3.68 \pm 1.85 \mathrm{D}$ in hypermetropia. There was a statistically significant difference in axial length of the worse and better eye in both myopic and hypermetropic anisometropia $(P=0.00)$. There was no significant difference between CMT of better and worse eyes in anisomyopia $(P=0.79)$, anisohypermetropia $(P=0.09)$, or anisoastigmatism $(P=0.16)$. In anisohypermetropia only inferior quadrant RNFL was found to be significantly thicker $(P=0.011)$ in eyes with greater refractive error.

Conclusion: There does not appear to be a significant difference in CMT and peripapillary RNFL thickness in anisomyopia and anisoastigmatism. However, in anisohypermetropia inferior quadrant RNFL was found to be significantly thicker.

Keywords: RNFL, CMT, anisometropia, amblyopia

\section{Introduction}

Anisometropia, an interocular difference in refraction, is an important condition in children as it can lead to significant visual problems including impaired stereopsis, amblyopia, ${ }^{2}$ and strabismus. ${ }^{3}$ Although there is no defined value, an interocular difference of 1 diopter (D) or more is accepted as the threshold for anisometropia by most authors. ${ }^{4-6}$ Anisometropia is broadly characterized as myopic, hypermetropic, and astigmatic. It represents unequal eye growth or stretch within a visual system which has presumably received the same visual input. Examination of the two eyes from the same subject allows for greater control of confounding variables like genetic and environmental influences. Anisometropia is therefore of great use in refractive error research. 
Ocular parameters in different types of anisometropia have been well studied in the past. ${ }^{46}$ Prior studies have established correlation of anisomyopia and anisohypermetropia with axial length, ${ }^{4,6}$ and that of anisoastigmatism with corneal curvature. ${ }^{5}$ Anisomyopia has also been correlated to vitreous chamber depth. ${ }^{7,8}$ Some studies have also found a significant difference in corneal curvature and anterior chamber depth between fellow eyes in anisohypermetropia. ${ }^{9}{ }^{10}$ However retinal architecture in anisometropia is still widely unexplored.

With the recent advancement of optical coherence tomography (OCT), we can reliably measure the retinal structures. OCT allows us to perform an optical biopsy of tissues by taking advantage of the differential optical refraction properties of the tissues. ${ }^{11}$ It is a noncontact, noninvasive easily reproducible method that uses only light. Most of the studies in the past have focused on differences in central macular thickness (CMT) and retinal nerve fiber layer (RNFL) thickness between fellow eyes in anisometropic amblyopia. ${ }^{12-15}$ Some studies found increase in RNFL thickness or macular thickness in the amblyopic eyes, ${ }^{14,16-19}$ while others did not observe any difference. ${ }^{20-23}$ Therefore the changes in RNFL thickness and macular thickness even in refractive amblyopia are not well established. Moreover, anisometropia per se has not been extensively studied using OCT in the past. Whether the differences in ocular anatomy in anisometropia have impact on retinal architecture needs to be explored further.

This study was therefore conducted to evaluate whether there was a difference in foveal and peripapillary RNFL between the two eyes of individuals having anisometropia $>1$ D.

\section{Materials and methods}

This prospective cross sectional study was performed from November 2013 to April 2015 in the Department of Ophthalmology of the University College of Medical Sciences (UCMS). The study protocol was approved by the institutional ethics committee-human research (IEC-HR/13) of UCMS. Written informed consent was obtained from all adult patients and the parents or legal guardians of all minor patients prior to enrollment, according to guidelines set forth in the Declaration of Helsinki.

The study included 202 eyes of 101 subjects between $10-40$ years of age having anisometropia of $1 \mathrm{D}$ or more. After informed consent, a detailed ophthalmological examination was performed for every patient including cycloplegic refraction, best corrected visual acuity (BCVA), slit lamp, and fundus examination. To induce pupil dilatation, one drop of tropicamide $0.8 \%$ was instilled three times, 10 minutes apart and auto refraction was performed. The mean of three successful measurements was taken for analysis. The cycloplegic spherical equivalent, ${ }^{24}$ (spherical component + half cylinder component) was used to calculate refractive error. An interocular difference of $1 \mathrm{D}$ or more in cycloplegic spherical equivalent was considered anisometropia. Amblyopia was defined as visual acuity of $20 / 30$ or worse, or a difference of two or more lines on Snellen's chart between better and worse eye.

Subjects with any of the following ocular pathology were excluded from the study: corneal opacity, cataract, nystagmus, history of previous ocular surgery, any retinal pathology, and those who were not sufficiently cooperative for ocular examinations. Children undergoing amblyopia treatment and using glasses for their refractive error were included in the study.

To assess BCVA, the patients were retested 3 days after cycloplegic refraction and Snellen acuity was measured. In order to calculate and compare visual acuity, Snellen acuity was converted to $\log M A R$ according to the conversion table mentioned by Holladay. ${ }^{25}$

All OCT scans were performed using Cirrus high-definition OCT (model 4000, Version 6; Carl Zeiss Meditec AG, Dublin, CA, USA). All the scans were performed using fast macular thickness and fast optic disc protocol. OCT scans with signal strength $<6$ out of 10 units and artifacts were excluded. In the fast macular thickness protocol, $6 \mathrm{~mm}$ lines in a radial spoke pattern are obtained in a continuous automated sequence. Internal fixation was used for all scans. The CMT was measured for each subject. The CMT is defined as the central circle of $1 \mathrm{~mm}$ diameter in the macular image. Peripapillary RNFL thickness was measured using the fast RNFL thickness (3.4 mm diameter) scan. The scans were obtained in high speed mode with the automated real time features enabled. The central circle of the RNFL scan which is called "global" and the inferior, temporal, superior, and nasal thickness were used to calculate the difference between the worse and the better eyes. The average of three sets of measurements was calculated and recorded for each parameter. All the data were extracted from OCT software; no manual measurements were made. Axial length was measured using an A scan biometer (Appa Scan-2000).

Refractive state of the eye is known to induce errors in RNFL or macular thickness OCT measurements. ${ }^{26,27}$ To compensate for magnification factors, a modified Littmann formula is commonly used in order to rescale RNFL or 
macular thickness measures.$^{28}$ The application of Littmann's formula incorporates only axial length in determining the magnification factor of the eye. ${ }^{28,29} \mathrm{Littmann}$ 's formula was used to compensate for the effect of ocular magnification.

For each participant, the worse eye with greater refractive error was compared to the better eye via paired $t$-tests using IBM software with $P<0.05$ considered significant. Correlations between parameters were studied using the Pearson correlation coefficient and simple linear regression.

\section{Results and observation}

The average age of 101 subjects was $21.7 \pm 9.3$ years (range $10-40$ years). There were 59 females and 42 males; the participant characteristics are presented in Table 1. The male:female ratio was 2:3 in anisomyopic and anisohypermetropic subjects, however in astigmatic anisometropia there were more females $(71.42 \%)$ compared to males $(28.57 \%)$. All the subjects had anisometropia of $1 \mathrm{D}$ or more with 31 subjects having anisomyopia, 42 anisohypermetropia, and 28 anisoastigmatism. The mean anisometropia was $3.11 \pm 1.7 \mathrm{D}$ in myopia, $2 \pm 0.99 \mathrm{D}$ in astigmatism and $3.68 \pm 1.85 \mathrm{D}$ in hypermetropia. The distribution of amblyopic subjects in the three groups is presented in Table 1.

The mean BCVA (logMAR) of the better and worse eye in the three groups of anisometropia is shown in Table 2. The interocular acuity difference was significant in all groups $(P<0.05)$. Anisohypermetropes had the worst visual acuity in the affected eye, when compared to anisomyopes and anisoastigmatic subjects.

There was a statistically significant difference in axial length of the worse and better eye in both myopic and hypermetropic anisometropia $(P=0.00)$ (Table 3).

The mean central macular thickness and the peripapillary RNFL thickness are illustrated in Table 4. We found no significant difference in mean central macular thickness and global peripapillary RNFL thickness in any group. However inferior quadrant RNFL thickness was found to be significantly thicker in anisohypermetropic subjects.

Table I Participant characteristics

\begin{tabular}{lllll}
\hline $\begin{array}{l}\text { Type of } \\
\text { anisometropia }\end{array}$ & $\begin{array}{l}\text { Mean } \\
\text { age } \\
(\text { years) }\end{array}$ & $\begin{array}{l}\text { Males, } \\
\mathbf{n}(\%)\end{array}$ & $\begin{array}{l}\text { Females, } \\
\mathbf{n}(\%)\end{array}$ & $\begin{array}{l}\text { Amblyopic } \\
\text { subjects, } \\
\mathbf{n}(\%)\end{array}$ \\
\hline Myopia $(\mathrm{n}=3 \mathrm{I})$ & 20.09 & $14(45.16)$ & $17(54.83)$ & $\mathrm{II}(35.4)$ \\
Astigmatic $(\mathrm{n}=28)$ & 23.75 & $8(28.57)$ & $20(7 \mathrm{I} .42)$ & $18(64.28)$ \\
Hypermetropia $(\mathrm{n}=42)$ & 21.52 & $20(47.6 \mathrm{I})$ & $22(52.38)$ & $40(95.23)$ \\
\hline
\end{tabular}

Table 2 Mean BCVA (logMAR) of the worse and the better eyes in different forms of anisometropia

\begin{tabular}{llll}
\hline Anisometropia & $\begin{array}{l}\text { Mean BCVA } \\
\text { worse eye } \\
\text { (logMAR) }\end{array}$ & $\begin{array}{l}\text { Mean BCVA } \\
\text { fellow eye } \\
\text { (logMAR) }\end{array}$ & $\begin{array}{l}\text { Interocular } \\
\text { acuity } \\
\text { difference }\end{array}$ \\
\hline Myopic & $0.35 I \pm 0.361$ & $0.1137 \pm 0.190$ & $\begin{array}{l}0.237 \\
(P=0.00)^{*}\end{array}$ \\
Astigmatic & $0.34 I \pm 0.238$ & $0.040 \pm 0.091$ & $\begin{array}{l}0.301 \pm 0.246 \\
(P=0.00)^{*}\end{array}$ \\
Hypermetropic & $0.941 \pm 0.432$ & $0.068 \pm 0.164$ & $\begin{array}{l}0.872 \pm 0.452 \\
(P=0.00)^{*}\end{array}$ \\
\hline
\end{tabular}

Notes: $* P$-value $<0.05$ significant. Data is presented as mean \pm standard deviation. Abbreviations: BCVA, best corrected visual acuity; $\log M A R$, logarithm of the minimum angle of resolution.

\section{Discussion}

With the recent advancement of OCT, retinal structures can be measured reliably. OCT has been extensively used in the past to study involvement of retina and optic nerve in anisometropic amblyopia. ${ }^{12-15}$ The earlier studies have shown conflicting results. In most studies, ${ }^{14,16-18}$ amblyopic eyes tended to have a thicker retina and/or RNFL. Yen et $\mathrm{al}^{14}$ measured RNFL thickness in patients with unilateral amblyopia (strabismic and refractive) and found no significant difference between the eyes of strabismic amblyopes; however, they found RNFL to be significantly thicker in refractive amblyopes. They postulated that amblyopic eyes have a thicker retina due to the arrest of the physiological postnatal ganglion cell reduction. Similar results were reported by Yoon et al, ${ }^{19}$ who also reported that RNFL was significantly thicker in patients with amblyopia. Bozkurt et al, ${ }^{20}$ using a third-generation retinal nerve fiber analyzer, reported no significant difference in the RNFL thickness in amblyopic and fellow eyes. Altintas et $\mathrm{al}^{21}$ reported that the RNFL thickness was thicker in amblyopic eyes, but that the difference was not statistically significant. Similar results were reported by Kee et al, ${ }^{22}$ Repka et al, ${ }^{17}$ and Firat et al. ${ }^{23}$ In contrast to these studies Yalcin and Balci $^{30}$ however, found significantly greater mean foveal

Table 3 Mean axial length of the worse and the better eye in different forms of anisometropia

\begin{tabular}{|c|c|c|c|c|}
\hline Anisometropia & $\begin{array}{l}\text { Mean AL } \\
\text { worse eye } \\
(\mathrm{mm})\end{array}$ & $\begin{array}{l}\text { Mean AL } \\
\text { better eye } \\
(\mathrm{mm})\end{array}$ & $\begin{array}{l}\text { Mean } \\
\text { difference } \\
(\mathrm{mm})\end{array}$ & $P$-value \\
\hline Myopic & $25.7 \pm 1.3$ & $24.117 \pm 1.21$ & $1.05 \pm 0.889$ & $0.00 *$ \\
\hline Astigmatic & $22.766 \pm 1.12$ & $22.789 \pm 0.85$ & $0.023 \pm 0.705$ & 0.869 \\
\hline Hypermetropic & $20.97 \pm 1.20$ & $22.11 \pm 1.05$ & $-1.14 \pm 0.89$ & $0.00 *$ \\
\hline
\end{tabular}

Notes: $* P$-value $<0.05$ significant. Data is presented as mean \pm standard deviation. Abbreviation: AL, axial length. 
Table 4 Comparison of CMT and RNFL thickness of the three types of anisometropia

\begin{tabular}{|c|c|c|c|c|}
\hline Type of anisometropia & Variable & Worse eye & Better eye & $P$-value \\
\hline \multirow[t]{6}{*}{ Anisomyopia } & CMT & $231.93 \pm 33.36$ & $233.0 \pm 24.47$ & 0.79 \\
\hline & RNFL & $80.5 \pm 13.08$ & $85.87 \pm 8.46$ & 0.079 \\
\hline & Superior RNFL & $95.27 \pm 25.129$ & $101.20 \pm 22.94$ & 0.16 \\
\hline & Inferior RNFL & $98.87 \pm 25.083$ & $108.37 \pm 20.54$ & 0.15 \\
\hline & Nasal RNFL & $64.10 \pm 17.39$ & $65.37 \pm 13.23$ & 0.78 \\
\hline & Temporal RNFL & $61.03 \pm 19.78$ & $59.13 \pm 7.812$ & 0.151 \\
\hline \multirow[t]{6}{*}{ Anisoastigmatism } & CMT & $233 \pm 34.36$ & $228 \pm 33.41$ & 0.16 \\
\hline & RNFL & $89.7 \pm 10.77$ & $90.107 \pm 8.94$ & 0.90 \\
\hline & Superior RNFL & $108 \pm 14.97$ & $102.75 \pm 20.04$ & 0.18 \\
\hline & Inferior RNFL & || $0.2| \pm| 5.88$ & $115.85 \pm 13.95$ & 0.2 \\
\hline & Nasal RNFL & $71.07 \pm 11.94$ & $69.178 \pm 13.85$ & 0.8 \\
\hline & Temporal RNFL & $68.3 \pm 21.3$ & $66.03 \pm 13.8$ & 0.20 \\
\hline \multirow[t]{6}{*}{ Anisohypermetropia } & CMT & $232 \pm 45.85$ & $224 \pm 27.64$ & 0.09 \\
\hline & RNFL & $90.02 \pm \mid 2.181$ & $89.97 \pm 11.14$ & 0.98 \\
\hline & Superior RNFL & $105.74 \pm 26.882$ & $|09.02 \pm 28.8|$ & 0.56 \\
\hline & Inferior RNFL & $|24 \pm| 7.4||$ & $117 \pm 14.636$ & $0.01 I^{*}$ \\
\hline & Nasal RNFL & $71.81 \pm 13.969$ & $70.07 \pm 15.256$ & 0.8 \\
\hline & Temporal RNFL & $62.57 \pm 17.796$ & $61.64 \pm 13.449$ & 0.82 \\
\hline
\end{tabular}

Notes: *P-value $<0.05$ significant. Data is presented as mean \pm standard deviation. Abbreviations: CMT, central macular thickness; RNFL, retinal nerve fiber layer.

thickness and similar RNFL thickness in hypermetropic amblyopes. In our study hypermetropic anisometropes had thicker global RNFL in the worse eye but the difference was not found to be statistically significant. Only inferior quadrant RNFL was found to be significantly thicker than the fellow eyes. We postulate that as per the ISNT rule (that normal eyes show a characteristic configuration of disc rim thickness of inferior $\geq$ superior $\geq$ nasal $\geq$ temporal), ${ }^{31}$ the inferior neuroretinal rim is the thickest and hence we found a significantly greater difference in inferior quadrant RNFL thickness. Our study corroborates with studies of Yen et al, ${ }^{14}$ and Yoon et al, ${ }^{19}$ as the majority of our anisohypermetropic subjects (40 out of 42) were amblyopes and these authors found a thicker RNFL in amblyopic eyes in their studies.

In the present study OCT measurements in anisomyopic subjects showed a thinner peripapillary RNFL in the more myopic eyes however the difference was not found to be statistically significant. Our study corroborated with previous studies, ${ }^{32-34}$ which have documented a thinner RNFL in myopic subjects. However, some studies have reported a significantly thinner RNFL in more myopic eyes; ${ }^{35}$ our study did not find a significant difference.

Previous studies ${ }^{36,37}$ on CMT in myopia have reported varying results. Jiang et $\mathrm{al}^{37}$ found CMT to be significantly thinner in the more myopic eyes. However, according to Vincent et $\mathrm{al}^{36}$ choroidal thickness and not retinal thickness is decreased in the more myopic eyes of anisomyopia as they found no significant difference in CMT but significant difference in choroidal thickness. Pathogenesis of myopia is multifactorial and complex. As myopia is contributed to by axial elongation, the elongation may cause mechanical stretching and thinning of the retina. ${ }^{38}$ This implies that extent of elongation of globe would be related to retinal thinning. We speculate that since our study excluded high myope patients with some pathological retinal findings, there were no significant differences in CMT. Jiang et a ${ }^{37}$ revealed that in people with myopic anisometropia, the more myopic eyes had a thinner parafoveal region than their fellow eyes while the foveal thickness was similar between two eyes. Parafoveal area may play a more important role than fovea. This was supported by a hypothesis that the decrease in peripheral retinal thickness may compensate for stretching force over the entire retina to preserve CMT in progression of myopia. ${ }^{39}$

In anisoastigmatism and anisohypermetropia, the central macula was thicker in the affected eye; however, the difference was not statistically significant in our study. Though most of the studies on CMT have been done on anisomyopia and refractive amblyopia, the CMT in anisohypermetropia and anisoastigmatism has not been explored much. Demircan et al, ${ }^{10}$ reported similar observations on CMT in anisohypermetropic subjects. To the best of our knowledge there are no studies in the literature on CMT in anisoastigmatism.

Thus we conclude that the majority of previous studies have found conflicting results using OCT in anisomyopia and anisohypermetropic amblyopia. There is no single consensus about the relation of OCT parameters with anisometropia. We believe that our study makes an addition to the literature examining all the three types of anisometropia, especially 
astigmatic anisometropia. We did not find any significant difference between the CMT and RNFL of fellow eyes in any type of anisometropia, thus the difference in ocular anatomy in anisometropia does not seem to contribute to variation in retinal architecture; except in hypermetropic anisometropia where we found a significantly greater inferior quadrant RNFL thickness, which may have been because the majority of subjects were amblyopic in this group.

Our study was limited by the small number of subjects. Moreover we did not have a control group of normal children and adults. A similar population based study on a larger group of subjects is needed to establish more statistically powerful results. Correlation between different parameters, specially with corneal curvature in anisoastigmatism will further improve our understanding in this field. Histopathological confirmation of the findings is needed in the future to further support our findings.

\section{Disclosure}

The authors report no conflicts of interest and have no proprietary interest in any of the materials mentioned in this article.

\section{References}

1. Gawecki M, Adamski J. [Anisometropia and stereopsis]. Klin Oczna. 2004;106(4-5):561-563. Polish.

2. Weakley DR Jr. The association between nonstrabismic anisometropia, amblyopia, and subnormal binocularity. Ophthalmology. 2001; 108(1):163-171.

3. Weakly DR Jr, Birch E, Kip K. The role of anisometropia in the development of accommodative esotropia. J AAPOS. 2001;5(3): 153-157.

4. O’Donoghue L, McClelland JF, Logan NS, Rudnicka AR, Owen CG, Saunders KJ. Profile of anisometropia and anisoastigmatism in children: prevalence and association with age, ocular biometric measures and refractive status. Invest Ophthalmolo Vis Sci. 2013;54(1):602-608.

5. Huynh SC, Wang XY, Ip J, et al. Prevalence and associations of anisometropia and anisoastigmatism in a population based sample of 6 year old children. Br J Ophthalmol. 2006;90(5):597-601.

6. Vincent SJ, Collins MJ, Read SA, Carney LG. Myopic anisometropia: ocular characteristics and aetiological considerations. Clin Exp Optom. 2014;97(4):291-307.

7. Kim SY, Cho SY, Yang JW, Kim CS, Lee YC. The correlation of differences in the ocular component values with the degree of myopic anisometropia. Korean J Ophthalmol. 2013;27(1):44-47.

8. Wong TY, Foster PJ, Ng TP, et al. Variations in ocular biometry in an adult Chinese population in Singapore: the Tanjong Pagar Survey. Invest Ophthalmol Vis Sci. 2001;42:73-80.

9. Strang NC, Schmid KL, Carney LG. Hyperopia is predominantly axial in nature. Curr Eye Res. 1998;17(4):380-383.

10. Demircan S, Gokce G, Yuvaci I, et al. The assessment of anterior and posterior ocular structures in hyperopic anisometropic amblyopia. Med Sci Monit. 2015;21:1181-1188.

11. Huang D, Swanson EA, Lin CP, et al. Optical coherence tomography. Science. 1991;254:1178-1181.

12. Al-Haddad CE, Mollayess GMEL, Cherfan CG, Jaafar DF, Bashshur ZF. Retinal nerve fibre layer and macular thickness in amblyopia as measured by spectral-domain optical coherence tomography. $\mathrm{Br} J$ Ophthalmol. 2011;95(12):1696-1699.
13. Colen TP, de Faber JT, Lemi HG. Retinal nerve fiber layer thickness in human strabismic amblyopia. Binocul Vis Strabismus Q. 2000;15(2): 141-146.

14. Yen MY, Cheng CY, Wang AG. Retinal nerve fiber layer thickness in unilateral amblyopia. Invest Ophthalmol Vis Sci. 2004;45(7):2224-2230.

15. Dickmann A, Petroni S, Salerni A, Dell’Omo R, Balestrazzi E. Unilateral amblyopia: An optical coherence tomography study. J AAPOS. 2009;13(2):148-150.

16. Huynh SC, Samarawickrama C, Wang XY, et al. Macular and nerve fiber layer thickness in amblyopia: the Sydney Childhood Eye Study. Ophthalmology. 2009;116(9):1604-1609.

17. Repka MX, Kraker RT, Tamkins SM, Suh DW, Sala NA, Beck RW. Retinal nerve fiber layer thickness in amblyopic eyes. Am J Ophthalmol. 2009;148(1):143-147.

18. Repka MX, Goldenberg-Cohen N, Edwards AR. Retinal nerve fiber layer thickness in amblyopic eyes. Am J Ophthalmol. 2006;142(2): 247-251.

19. Yoon SW, Park WH, Baek SH, Kong SM. Thicknesses of macular retinal layer and peripapillary retinal nerve fiber layer in patients with hyperopic anisometropic amblyopia. Korean J Ophthalmol. 2005; 19(1):62-67.

20. Bozkurt B, Irkeç M, Orhan M, Karaağaoğlu E. Thickness of the retinal nerve fiber layer in patients with anisometropic and strabismic amblyopia. Strabismus. 2003;11(1):1-7.

21. Altintas O, Yüksel N, Ozkan B, Caglar Y. Thickness of the retinal nerve fiber layer, macular thickness, and macular volume in patients with strabismic amblyopia. J Pediatr Ophthalmol Strabismus. 2005;42(4): 216-221.

22. Kee SY, Lee SY, Lee YC. Thicknesses of the fovea and retinal nerve fiber layer in amblyopic and normal eyes in children. Korean $J$ Ophthalmol. 2006;20(3):177-181.

23. Firat PG, Ozsoy E, Demirel S, Cumurcu T, Gunduz A. Evaluation of peripapillary retinal nerve fiber layer, macula and ganglion cell thickness in amblyopia using spectral optical coherence tomography. Int J Ophthalmol. 2013;6(1):90-94.

24. Thibos LN, Wheeler W, Horner D. Power vectors: an application of Fourier analysis to the description and statistical analysis of refractive error. Optom Vis Sci. 1997;74(6):367-375.

25. Holladay JT. Proper method for calculating average visual acuity. J Refract Surg. 1997;13:388-391.

26. Garway-Heath DF, Rudnicka AR, Lowe T, Foster PJ, Fitzke F, Hitchings R. Measurement of optic disc size: Equivalence of methods to correct for ocular magnification. Br J Ophthalmol. 1998;82: 643-649.

27. Bengtsson B, Krakau CE. Correction of optic disc measurements on fundus photographs. Graefes Arch Clin Exp Ophthalmol. 1992;230: 24-28.

28. Patel NB, Garcia B, Harwerth RS. Influence of anterior segment power on the scan path and RNFL thickness using SD-OCT. Invest Ophthalmol Vis Sci. 2012;53:5788-5798.

29. Bennett AG, Rudnicka AR, Edgar DF. Improvements on Littmann's method of determining the size of retinal features by fundus photography. Graefes Arch Clin Exp Ophthalmol. 1994;232:361-367.

30. Yalcin E, Balci O. Peripapillary retinal nerve fibre layer and foveal thickness in hypermetropic anisometropic amblyopia. Clinical Ophthalmol. 2014;8:749-753.

31. Ditchtl A, Jonas JB, Nauman GO. Retinal nerve fibre layer thickness in human eyes. Graefes Arch Clinical Exp Ophthalmol. 1999;237(6): 474-479.

32. Leung CK, Mohamed S, Leung KS, et al. Retinal nerve fiber layer measurements in myopia: An optical coherence tomography study. Invest Ophthalmol Vis Sci. 2006;47(12):5171-5176.

33. Choi SW, Lee SJ. Thickness changes in the fovea and peripapillary retinal nerve fiber layer depend on the degree of myopia. Korean $J$ Ophthalmol. 2006;20(4):215-219.

34. Rauscher FM, Sekhon N, Feuer WJ, Budenz DL. Myopia affects retinal nerve fiber layer measurements as determined by optical coherence tomography. J Glaucoma. 2009;18(7):501-505. 
35. Tekin K, Cankurtaran V, Inanc M, Sekeroglu MA, Yilmazbas P. Effect of myopic anisometropia on anterior and posterior segment ocular parameters. Int Ophthalmol. 2016 Jun 4. [Epub ahead of print].

36. Vincent SJ, Collins MJ, Read SA, Carney LG. Retinal and choroidal thickness in myopic anisometropia. Investig Ophthalmol Vis Sci. 2013; 54(4):2445-2456.

37. Jiang Z, Shen M, Xie R, Qu J, Xue A, Lu F. Interocular evaluation of axial length and retinal thickness in people with myopic anisometropia. Eye Contact Lens. 2013;39(4):277-282.
38. Apple DJ, Fabb MF. Clinicopathologic correlation of ocular disease: a text and stereoscopic atlas. St. Louis, MO: CV Mosby. 1978.

39. Lam DS, Leung KS, Mohamed S, et al. Regional variations in the relationship between macular thickness measurements and myopia. Invest Ophthalmol Vis Sci. 2007;48(1):376-378.

\section{Publish your work in this journal}

Clinical Ophthalmology is an international, peer-reviewed journal covering all subspecialties within ophthalmology. Key topics include: Optometry; Visual science; Pharmacology and drug therapy in eye diseases; Basic Sciences; Primary and Secondary eye care; Patient Safety and Quality of Care Improvements. This journal is indexed on

\section{Dovepress}

PubMed Central and CAS, and is the official journal of The Society of Clinical Ophthalmology (SCO). The manuscript management system is completely online and includes a very quick and fair peer-review system, which is all easy to use. Visit http://www.dovepress.com/ testimonials.php to read real quotes from published authors. 